\title{
História e Filosofia das Geociências: relevância para 0 ensino e formação profissional $^{* 1}$
}

\author{
Silvia Fernanda de Mendonça Figueirôa \\ Departamento de Geociências Aplicadas ao \\ Ensino, Instituto de Geociências (Unicamp) \\ figueiroa@ige.unicamp.br
}

\footnotetext{
* Este artigo deve ser referido como segue:
}

Figueirôa S. F. M., 2009. História e Filosofia das Geociências: relevância para 0 ensino e formação profissional. Terræ Didatica, 5(1):63-71<http:// www.ige.unicamp.br/ terraedidatica/>

1 Este artigo é 0 texto integral, com alguns acréscimos, da palestra proferida no $44^{\circ}$ Congresso Brasileiro de Geologia (Curitiba-PR, 2008), no âmbito do Simpósio 45 (História, Filosofia e Divulgação em Geociências). Agradeço ao colega Maurício Compiani, bem como aos participantes da sessão e aos dois referees, pelos comentários e questões que me auxiliaram a melhorar 0 texto.

\begin{abstract}
HISTORY AND PHILOSOPHY OF GEOSCIENCES: RELEVANCE FOR EDUCATION AND TRAINING. This article points out some important relations between the history and philosophy of sciences, and geosciences education to the professional formation of geoscientists and future teachers. After a brief survey of the discussions on the relations between the above mentioned fields all long the past 50 years, aiming at stressing some pedagogical roles that history, and philosophy of sciences may play, the text uses a recent geological example in order to put together conclusions advanced by some classical papers about sciences and geosciences. It concludes by reinforcing the relevance of historical and epistemological reflections for the improvement of professional formation, and for the renewal of educational practices.
\end{abstract}

KEYWORDS History of science, philosophy of science, geosciences education.

RESUMO Este artigo aponta relações importantes entre a História, a Filosofia e a Educação em Geociências para a formação profissional de geocientistas e futuros professores. Parte de um breve levantamento das discussões acerca das relações entre os mencionados campos do conhecimento ao longo dos últimos 50 anos, salientando alguns papéis didáticos que a História e a Filosofia podem desempenhar. A seguir, usa um exemplo recente em Geologia para articular as reflexões de alguns trabalhos clássicos sobre as Ciências e as Geociências. Conclui reforçando a relevância das reflexões históricas e epistemológicas para aprimoramento da formação profissional e para a renovação de práticas educativas.

PALAVRAS-CHAVE História das ciências, filosofia das ciências, ensino de Geociências. 


\section{Introdução}

Há quase 20 anos, tive a oportunidade de discutir as relações entre a História da Geologia e a formação dos geólogos num artigo publicado na Revista Brasileira de Geociências (Figueirôa 1989). Neste texto, minha principal motivação relacionava-se ao preocupante quadro de alta evasão nos cursos de Geologia que se verificava à época e a proposta central era:

“(...) mostrar o papel duplamente benéfico que pode serjogado pela História das Ciências Geológicas, tanto na reflexão e busca de novos rumos para a Geologia quanto no aprimoramento da formação profissional, de modo a formar o almejado geólogo crítico, capaz de contribuir, com sua prática técnico-científica, à superação da própria crise" (Figueirôa op.cit.:507).

Esse panorama sombrio, felizmente, se alterou de forma positiva e notável. A pergunta, portanto, que faço atualmente e à qual vou procurar responder neste texto é: ainda há um papel para a História e a Filosofia das Ciências geológicas na educação? Em caso afirmativo, qual?

\section{História, filosofia \& ensino: uma breve revisão e alguns exemplos}

Tanto a História quanto a Filosofia das Ciências em geral são disciplinas estabelecidas há mais de século, bem como os vários ramos das Geociências, particularmente da Geologia. Do mesmo modo, o ensino de Ciências, incluindo o de Geociências, também acumula reflexões e propostas há muitas décadas. Basicamente, as sugestões de associação entre História e Filosofia das Ciências e Educação passaram a ocorrer de forma mais sistemática após o segundo pós-guerra, em grande medida como resposta às trágicas consequências das aplicações da Ciência \& Tecnologia, principalmente as pesquisas que culminaram na produção da bomba atômica. A partir de questionamentos dos efeitos nefastos da aliança Ciência \& Tecnologia (daqui em diante, C $\& \mathrm{~T}$ ), propunha-se que a educação científica servisse para a formação de uma 'consciência cidadã' das implicações sociais e tecnológicas da Ciência (Figueirôa \& Lopes 1996). Uma proposta concreta foram os Harvard Case Histories, implantados na década de 1950 pelo então reitor James B. Connant.
Na mesma época, em 1953, uma palestra do físico Bernhard I. Cohen para professores propunha a adoção de uma percepção histórica na Ciência (Cohen 1993). ${ }^{1}$

Nota-se que tal temática não é nova e inúmeros trabalhos vêm sendo publicados, há muito tempo. No Brasil, a História das Ciências e da Tecnologia é ministrada nos cursos de Física, Química, Biologia, História e Arquitetura da USP desde os anos 196070. Nos eventos organizados pela Sociedade Brasileira de História da Ciência (SBHC), assim como nos da Sociedade Latino-americana de História das Ciências e da Tecnologia (SLHCT), temas relativos à História das Ciências \& Tecnologia e ensino têm estado presentes com regularidade desde os primeiros encontros nos anos 1980. No âmbito das Ciências geológicas, cabe destacar o pioneirismo do curso de graduação em Geologia do IG/UNICAMP, que incluiu "História das Ciências Naturais" como disciplina obrigatória desde sua criação, em 1997, assim como da recente Licenciatura em Geociências da USP, que inseriu "História das Ciências" em sua grade curricular. No Programa de Pós-Graduação em Geociências do Instituto de Geociências da UFRGS foi introduzida desde 1994 a disciplina GEP19-2 Epistemologia da Geologia e, no curso de graduação dessa mesma instituição, a disciplina Geo 04021 Epistemologia e História da Geologia, passou a figurar desde 2003. Igualmente, os núcleos básicos dos recém-criados cursos da Universidade Federal do ABC e da Faculdade de Ciências Aplicadas da UNICAMP, esta no novo campus em Limeira, incorporaram as disciplinas de História e Filosofia das Ciências.

Embora as reflexões datem de décadas, atualmente ainda se questiona a relevância da História e Filosofia das Ciências, como se vê pela seção Focus do mais recente número da quase centenária ISIS, revista internacional de História das Ciências, cujos editores se perguntam: "Que diferença, afinal, faz a História das Ciências?" (Maienschein \& Smith 2008). O conjunto de artigos apresentados nesse número, fruto de debates de um colóquio, acaba por responder afirmativamente à questão, reforçando a validade da História e Filosofia das Ciências tanto para os cientistas quanto para o ensino de Ciências, e também para a formulação de políticas de C \& T. No caso do ensino, são corroborados os diversos papéis que a História das Ciências pode

1 Esta palestra conheceu uma republicação comemorativa 40 anos depois, em 1993. 
desempenhar na educação, como aqueles já listados por Michael Matthews, editor da revista Science and Education, em artigo de 1992. Para este autor, a História das Ciências poderia:

"Humanizar as Ciências e aproximá-la mais dos interesses pessoais, éticos, culturais e políticos; tornar as aulas mais estimulantes e reflexivas, incrementando a capacidade do pensamento crítico; contribuir para uma maior compreensão dos conteúdos científicos, [...]; melhorar a formação dos professores contribuindo para o desenvolvimento de uma epistemologia da Ciência mais rica e mais autêntica, isto é, um melhor conhecimento da estrutura de Ciência e de seu lugar no marco intelectual das coisas” (Mathews 1995: 165).

Outros, como Diana Obregón (Obregón 1996: 543), afirmam que a História da Ciência deve se constituir em:

“(...) valiosa ferramenta tanto para o ensino como para o próprio trabalho científico. O conhecimento da história de uma Ciência permite desenvolver a capacidade crítica, o espírito de análise e de precisão, $e$ a atitude atenta e curiosa indispensável para o pensamento científico".

Outro papel relevante para a História e Filosofia das Ciências na educação científica tem sido o de localizar os 'conceitos estruturantes' dos conteúdos a serem ensinados. Gagliardi (1986: 31) assim os definiu e destacou sua importância: “um conceito cuja construção transforma o sistema cognitivo, permitindo adquirir novos conhecimentos, organizar os dados de outra maneira, transformar inclusive os conhecimentos anteriores". Para este autor, a história das Ciências teria um papel primordial no processo de identificação destes conceitos para cada conjunto de conhecimentos (Gagliardi \& Giordan 1986). Outros autores, como Compiani \& Gonçalves (1996), apresentam uma concepção mais ampliada dos 'conceitos estruturantes', que envolveriam não apenas o conteúdo específico, mas também os aspectos metodológicos e contextuais mais gerais. Numa concepção ou noutra, o fato é que a História e a Filosofia das Ciências jogam uma parte fundamental.

Sem dúvida, no mundo contemporâneo, com todas as intensas e rápidas mudanças científicas e tecnológicas, a História e a Filosofia das Ciências podem significar caminhos privilegiados não somente para a formação de cientistas, mas dos cidadãos em geral. Para mencionar um exemplo de atualidade e importância crescentes, até mesmo para as Geociências, tomemos a expansão do fundamentalismo cristão, o ressurgimento do Criacionismo e os ataques ao Darwinismo e à Ciência em geral. A História das Ciências poderia auxiliar a compreensão dos conflitos existentes, trazendo à atualidade as consequências para o ensino e aprendizagem das disciplinas que envolvem estes temas, não somente nos níveis fundamental e médio, mas também no ensino universitário, de onde não estão ausentes ${ }^{2}$. Os historiadores das Ciências há muito reconheceram que a imagem de conflito entre "Ciência", de um lado, e "Religião", no outro oposto, é produto de circunstâncias sociais e políticas específicas do final do século XIX. Como lembra o historiador das Geociências Martin Rudwick (2005: 6), até o final do século XVII todos os cronólogos - aqueles dedicados à Ciência da Cronologia, como o famoso Bispo Ussher, da Irlanda, que calculou a data exata de criação da Terra, ou o próprio Isaac Newton, dentre vários outros -, tentavam dar precisão àquilo que era, naquele tempo, geralmente aceito sem maiores discussões, ou seja: o mundo tinha uma história curta e finita, quase equivalente, em termos de duração, à história humana. Mesmo quando as rochas e, sobretudo, os fósseis foram introduzidos nos debates no final do século XVII, acabaram sendo integrados com naturalidade, e até com relativa facilidade, neste contexto de tempo curto e finito. Deste modo, as Sagradas Escrituras, e o que viria a ser posteriormente chamado de Geologia, se combinaram sem grandes problemas. Já em finais do século XVIII, graças especialmente a James Hutton, a maioria dos naturalistas, fossem religiosos ou não, aceitava com facilidade uma escala de tempo imensamente expandida para a Terra. Darwin, ao propor uma teoria da evolução afastada da idéia lamarckista (isto é, de evolução pela adaptação ao meio), e que tinha como mecanismo a seleção natural, acabou por alterar esta situação e provocar celeuma, pois a evolução por meio da seleção natural contradizia o Gênesis tomado em sentido literal (Ruse 2002: 18).

Assim, a História das Ciências tem muito a ensinar sobre como se desenvolveu o debate entre tempo bíblico e tempo geológico, Evolucionismo

2 Ver interessante artigo Criacionismo e darwinismo confrontam-se nos tribunais... da razão e do direito, de Paulo Abrantes e Fábio de Almeida, em Episteme 24, 2006. URL:http://www.ilea.ufrgs.br/episteme/portal/ index.php . 
e Criacionismo, seus pontos em comum e os conflituosos. Como já afirmado em outro trabalho (Souza \& Figueirôa 2008), acredito que somente a partir da percepção de que as relações entre práticas religiosas e crenças, e práticas científicas e crenças variam enormemente no mundo atual, assim como variaram amplamente no passado segundo o tempo, o lugar e, mais do que tudo, segundo os contextos sociais e culturais, é que se poderá contribuir, de maneira positiva, para a superação das dicotomias obscurantistas, sem obrigar ninguém à aceitação ou negação de qualquer credo, nem à rejeição do conhecimento científico.

\section{A formação dos profissionais}

Além destas observações gerais que vimos desenvolvendo até aqui, o que mais se poderia dizer sobre a importância da História e Filosofia das Geociências na formação específica dos futuros profissionais e professores, a fim de avançar na constatação já feita em 1877 pelo geólogo alemão Bernhard von Cotta, para quem "a Geologia, como todas as demais Ciências, é resultado de seu passado, e é por isso que o estudo do precedente é necessário à compreensão do subseqüente" (von Cotta 1877, apud Guntau e Kirschner 1984). Partirei, para minha reflexão, de um instigante artigo-testemunho há pouco publicado na Revista Brasileira de Geociências, de autoria de Jorge Carlos della Favera e Marco André Malmann Medeiros (Favera e Medeiros 2007). Neste trabalho, os autores discutem como foi possível o reconhecimento, por parte de um deles, pela primeira vez no Brasil (na Bacia do Parnaíba), de

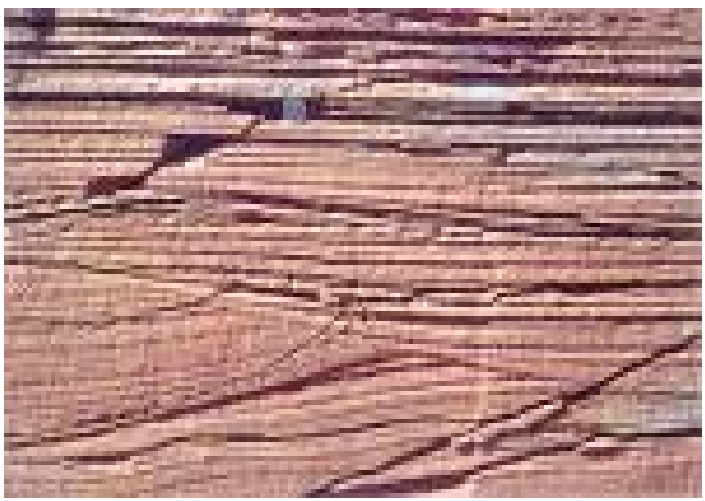

Figura 1 - Estratificação cruzada tipo Hummocky (Fonte: http://www.rgeology.com.ly/humocky\%20 cross\%20stratification\%20in\%20outcrop.JPG. Acesso em 27/04/09) estruturas do tipo hummocky - estrutura sedimentar que é uma variedade complexa de estratificação cruzada (Fig. 1) - e, a partir daí, a generalização de sua ocorrência para várias outras bacias sedimentares brasileiras.

A constatação que está na base das ponderações conduzidas por Favera e Medeiros pode ser resumida na seguinte citação:

\begin{abstract}
“(...) decorreram vários anos de mapeamento geológico por geólogos experientes antes que estas estruturas pudessem ser reconhecidas como uma estrutura sedimentar muito comum nas bacias intracontinentais.” (Favera e Medeiros op.cit.: 841) (grifos meus).
\end{abstract}

Não estamos diante, portanto, de um caso de incompetência profissional, ou de trabalhos apressados e superficiais, mas de algo mais profundo ligado à percepção-compreensão e também à aprendizagem. Para os autores, "este reconhecimento [das estruturas] só pode ser feito usando-se de maneira inconsciente o enfoque Gestalt" (Favera e Medeiros op.cit.: 841). Resumida e simplificadamente, a teoria psicológica da Gestalt é utilizada para explicação da percepção visual, e estabelece que não se pode conhecer o todo a partir das suas partes (ou seja, dividindo-se o objeto à moda Cartesiana), mas é o conjunto das partes que constrói o todo. Um exemplo amplamente popularizado, presente até em restaurantes à beira de estradas, é o da ilustração da face de Jesus Cristo composta de uma série de

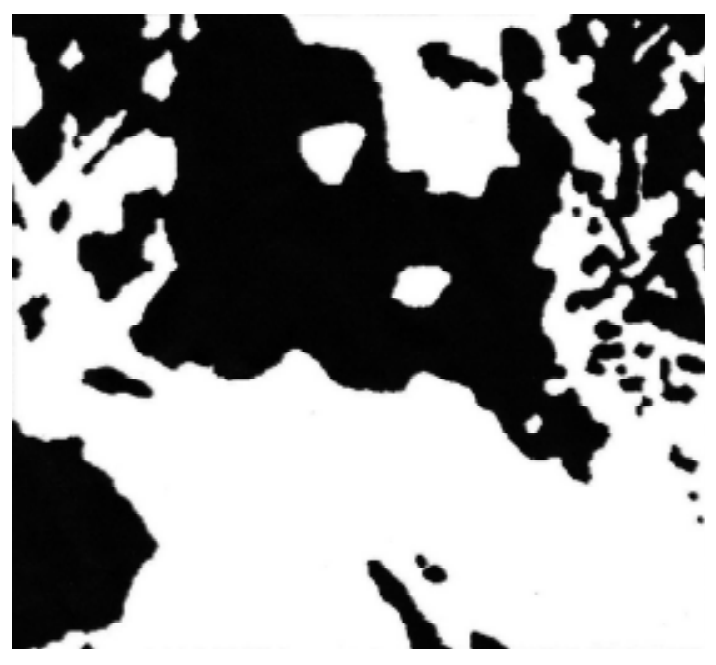

Figura 2 - Ilustração da face de Jesus Cristo (Fonte: http://ojs.c3sl.ufpr.br/ojs2/index.php/rbg/article/ view/11449/7980. Acesso em 27/04/09) 
manchas pretas sobre um fundo branco, encimada pela frase: "Quem me vê jamais me esquece" (Fig. 2). $\mathrm{Na}$ base deste tipo de evento perceptivo reside o princípio de que, uma vez visualizada, sempre será possível ver a imagem desta forma e mesmo, no limite, alternar os modos de ver. ${ }^{3}$

Esta linha de raciocínio tem, evidentemente, implicações relevantes para a formação dos alunos. Portanto, se não foi por incompetência, qual a explicação? Não se trata, a meu ver, de mais uma vez enfatizar a importância crucial das atividades de campo para a prática científica das Geociências e, por conseguinte, para a educação profissional, que aqui assumo como pressuposto por compartilhar das conclusões das pesquisas que vêm sendo desenvolvidas há muito tempo pelo nosso grupo do Departamento de Geociências Aplicadas ao Ensino do IG-UNICAMP. Trata-se de conhecer e questionar mais a fundo o modo como temos desenvolvido estes trabalhos. Atividades didáticas, incluindo as de campo, bem conduzidas e planejadas nos cursos de graduação são condição necessária, mas talvez não suficiente, para a boa formação profissional.

Para continuar esta reflexão, sugiro retomar o raciocínio desenvolvido por Paschoale (1984), a propósito dos trabalhos de campo no ensino de Geologia. Apoiado na Semiótica de Charles Sanders Peirce (1839-1914), o autor parte do questionamento daquilo que estaríamos (ou ainda estamos) ensinando a nossos alunos - se os fenômenos ou a representação dos fenômenos. Fundamentais em seu raciocínio são os conceitos de:

1) 'signo' - "algo que representa um objeto por força de uma característica ou qualidade, e que provoca na mente um interpretante" e é "através dele que nos comunicamos” (Paschoale op.cit.: 5.245-46);

2) 'interpretante' - "os conceitos, esquemas teorias, hipóteses, condutas" que utilizamos na produção do conhecimento podem ser chamados "genericamente de interpretantes" (Paschoale op.cit.: 5.245).

Das constatações a que Paschoale chega, a mais geral é que:

“(...) a prática, ou o fazer Geologia, é um processo de construção de interpretantes, de produção de signos. Ao

3 Veja-se a apresentação mais detalhada da Teoria da Gestalt no artigo supracitado. atribuir significados a feições observadas no planeta, ao associá-las em cadeias explicativas, ao montar teorias e propor testes, o geólogo vai, dialeticamente, aumentando seu conhecimento sobre o planeta" (Paschoale op.cit.: 5.246).

Dentre outros, o autor cita um exemplo básico como o da conceituação de 'granito'. Como se sabe, na prática técnico-científica, a definição deste tipo de rocha surgiu a partir de um conjunto vastíssimo de observações, descrições e análises de rochas reais e bastante variadas, e envolveu a clássica controvérsia entre plutonistas e netunistas na transição para o século XIX. No momento de seu ensino, no entanto, o granito é uma rocha ideal da qual todos os granitos existentes são um exemplo, “manifestações aproximadas. (...) [Aqueles] encontrados no campo, [são] simples exemplos, manifestações talvez muito complexas, cuja análise é feita em função do modelo ideal" (Paschoale op.cit.: 5.247). A decorrência disso é conhecida: as anotações de campo, muitas vezes, não são apenas descrições, mas justificativas, conforme os modelos idealizados. Representam um enorme esforço dos alunos para adequarem suas observações ao que, de antemão, por meio da bibliografia e, ou do professor, foram informados de que deva ser visto. As estruturas hummocky, por exemplo, ou qualquer outra 'novidade', passam assim despercebidas, invisíveis a olhos até bem treinados. A experiência gestáltica ou abductiva ${ }^{4}$ está dificultada, senão bloqueada.

Em tempo: não estou propondo que nossos alunos vão a campo sem qualquer orientação e produzam mapas desatualizados ou de qualidade duvidosa, mas sim que, neste processo de formação em que se constitui o trabalho de campo, haja espaço para o não-previsto, para o encontro do novo, para o 'insight'. É inegável que nossos 'modos de ver' - e, por conseguinte, os 'interpretantes' que geramos - estão necessariamente permeados pelo conjunto de conceitos prévios que carregamos, sejam eles científicos, culturais, pessoais etc. Além disso, como discute Rachel Laudan (1982), as Ciências geológicas se constituíram na tensão dialética entre as vertentes da História Natural e da Filosofia Natural. Ou seja, segundo a autora, o ramo a que

4 'Abducção' é um termo introduzido por Charles S. Peirce que procura definir um dos processos de formulação de hipóteses, aplicável à compreensão de um fenômeno não previsto pelas leis em vigor. Basicamente, o raciocínio abductivo diz: "Se ocorre $C$ então ocorre $D$. Ocorreu $D$, logo ocorreu $C$ ". opõe-se à 'indução' e tem grande relevância para o raciocínio geológico, no qual lidamos com registros de eventos passados sem testemunharmos o processo que os gerou. 
modernamente chamamos de Geologia resultou da união conflituosa entre, de um lado, os trabalhos exaustivamente descritivos empreendidos pela História Natural, que extraía assim suas leis pela generalização de um conjunto de dados empíricos (e, quanto maior o conjunto, mais preciso o enunciado); e, de outro, as teorias da Filosofia Natural, que se pretendiam generalizantes e explicativas dos fenômenos a partir de hipóteses e conclusões verificáveis a posteriori (método hipotético-dedutivo). Deste modo, portanto, a prática das Ciências geológicas embute um olhar que teoriza enquanto descreve, e que descreve impregnado da teoria.

Então, como seria possível ver de outro modo e 'inovar'? A História das Ciências e das Geociências, afirmo, poderia nos mostrar uma alternativa.

\section{Há diálogo com a História e a Filosofia das Ciências?}

Ao tratar de explicar as mudanças profundas e irreversíveis no pensamento científico em geral, Thomas Kuhn, em seu clássico livro $A$ estrutura das revoluções científicas, de 1962, também recorreu à teoria da Gestalt. Algumas de suas observações são bastante pertinentes para a argumentação até aqui desenvolvida. Kuhn sustenta, por exemplo, que:

“(...) durante as revoluções [os momentos de mudanças de paradigma], os cientistas vêem coisas novas $e$ diferentes quando, empregando instrumentos familiares, olham para os mesmos pontos examinados anteriormente. É como se a comunidade profissional tivesse sido subitamente transportada para um novo planeta, onde objetos familiares são vistos sob uma luz diferente. (...) as mudanças de paradigma realmente levam os cientistas a ver o mundo definido por seus compromissos de pesquisa de uma maneira diferente. (...) As bem conhecidas demonstrações relativas a uma alteração na forma visual ('Gestalt') demonstram ser muito sugestivas.” (Kuhn 1975: 145-46).

As reflexões de Kuhn também envolvem o ensino, embora de maneira não prioritária. Ao falar da educação científica, o autor define o aprendizado como sendo a "inculcação", ou o treino, num paradigma e que envolve, obrigatoriamente, mudanças gestálticas:

“(...) transformações dessa natureza, embora usualmente sejam mais graduais e quase sempre irreversí- veis, acompanham comumente o treinamento científico. Ao olhar uma carta topográfica, o estudante vê linhas sobre o papel; o cartógrafo vê a representação de um terreno. Ao olhar a fotografia da câmara de Wilson, o estudante vê linhas interrompidas e confusas; o físico vê um registro de eventos sub-nucleares que the são familiares” (Kuhn op.cit.: 146).

A esse quadro, podemos acrescentar: onde um leigo vê formas de cores distintas e linhas escuras, o geocientista vê unidades estratigráficas, falhas e contatos. Porém, as mudanças do conhecimento são contínuas e os paradigmas mudam, alterando nossa forma de explicar e ver o mundo.

É oportuno acrescentar, em reforço a estas reflexões que, em livro recente sobre a história da noção de objetividade em Ciência Lorraine Daston e Peter Galison demonstram, com exaustivos exemplos, que no cerne da concepção de objetividade científica estão embutidos diferentes modos de ver que são, ao mesmo tempo, sociais, epistemológicos, e éticos. Aprendidos coletivamente, não devem sua existência a nenhum indivíduo ou laboratório, sequer a uma disciplina (Daston \& Galison 2007:10). Assim, modos de ver tornam-se modos de conhecer: os hábitos visuais, de identificação e coleta de dados, expressam "lealdades epistemológicas" - isto é, um conjunto de características intrínsecas a uma determinada disciplina - que, ao operarem na leitura do mundo natural, definem e constroem os próprios dados (Daston \& Galison 2007: 368). Para estes autores,

“aprender a observar e a representar numa Ciência é
adquirir, ao mesmo tempo, um ethos e um modo de
ver. Os mesmos bem desenvolvidos padrões de aten-
ção, que destacam certos objetos num certo recorte, (...)
também padronizam/moldam um self” (Daston \&
Galison 2007: 367).

Em outros termos, dentro da multiplicidade que constitui a comunidade científica coexistem não somente individualidades, mas também distintas tradições coletivas de educação e sustentação dos selfs científicos, que se perpetuam por meio dos mesmos mecanismos que as tradições de pesquisa. Dizendo de outro modo: a produção de uma imagem científica é parte da produção de um self científico, e ambos são adquiridos por meio da prática contínua das técnicas de representação da natureza simultaneamente à moldagem do self (Daston \& Galison 2007: 363). 
A História das Ciências, portanto, poderia ser definida como a narrativa explicativa dos momentos de continuidade - i.é., de Ciência 'normal' (no sentido kuhniano) -, e de rupturas - i.é., das mudanças de paradigma, às vezes revolucionárias. Esta concepção de História das Ciências nos permite valorizar as controvérsias científicas e perceber que todo conhecimento é, em si mesmo, transitório; que novas percepções e interpretações podem surgir constantemente, subvertendo explicações e crenças científicas bem enraizadas, bem fundamentadas, bem demonstradas. Enfim, que há espaço para o novo, ainda que ele seja, muitas vezes, descartado a priori, como a já bem conhecida rejeição à Deriva Continental nas primeiras décadas do século passado.

No caso específico das Ciências geológicas, de que forma pode surgir este 'novo'? O já citado historiador das Geociências, Martin Rudwick, defende um ponto de vista criativo e fascinante em seu artigo Geological travel and theoretical innovation: the role of 'liminal' experience (1996), que apresentarei e ilustrarei com um exemplo do Brasil. Para Rudwick, em uma Ciência apoiada no campo como a Geologia, a inovação teórica pode demandar, ou ser estimulada, provocada, por meio de um processo similar ao da peregrinação religiosa, durante o qual os cientistas são expostos a informações perceptivas e pessoais não-familiares enquanto estão temporariamente isolados do seu ambiente científico familiar. Este isolamento em relação ao que é previamente conhecido provocaria, a princípio, um 'estranhamento', favorecendo a reorganização mental e a inovação explicativo-interpretativa - ou seja, a experiência gestáltica ou abductiva. No caso religioso, ocorre um aumento da percepção interior, das conexões intra e extra-psíquicas que geralmente conduzem o peregrino a uma nova compreensão de sua relação com deus (ou com os deuses). No caso científico, a viagem em situação de isolamento (a experiência-limite) permitiria o distanciamento, a progressiva libertação das amarras dos argumentos de autoridade dentro dos quais o pesquisador foi educado e ensinado a ver: a saber, o mestre, o tutor, os manuais, o local geográfico e geológico em que foi treinado, a comunidade técnico-científica mais próxima, a tradição de pesquisa, os paradigmas, enfim. Nas palavras do autor:

“(...) o que acontece se o geólogo faz o trabalho de campo longe da área 'natal' em que recebeu seu trei- namento? A inovação conceitual emerge do impacto perceptivo de feições desconhecidas ou surpreendentes numa mente que, de fato, já estava preparada pelo adestramento na interpretação de feições mais familiares". (Rudwick op.cit.: 144)

Para que isso ocorra é necessário fazer um trabalho de campo mais longo, em local previamente desconhecido, e de modo autônomo. Concretamente, na prática de nossos cursos de graduação, tal situação pode ser vivida nos mapeamentos mais ao final de curso ou nos TCCs [Trabalhos de Conclusão de Curso]. Mas não somente: talvez algumas doses a mais de autonomia aos iniciantes poderiam ser benéficas.

Um exemplo histórico que investiguei junto com o prof. William Brice, utilizando o referencial da experiência-limite acima mencionado, pode bem ilustrar este ponto de vista. Refere-se à controvérsia acerca da existência, ou não, de glaciações pleistocênicas no Brasil (Brice \& Figueirôa 2001). Durante a segunda metade do século XIX, o fato de geleiras tropicais terem ou não avançado por toda a América do Sul foi um tópico de discussão importante. A polêmica baseou-se, principalmente, nas observações feitas por Louis Agassiz (1807-1873) e outros, dentre os quais Charles Frederick Hartt (1840-1878) em particular, durante a Expedição Thayer ao Brasil nos anos de 1865 a 1866. Hartt e Agassiz, respectivamente aluno e professor, ao final acabaram em lados opostos desta controvérsia. Agassiz veio para o Brasil em busca de provas de glaciação nos trópicos a fim de apoiar sua posição anti-Seleção Natural, e viu o que esperava. Agassiz estava tão certo da glaciação que passou a viagem de navio a dar aulas diárias, a Hartt e a outros jovens assistentes, sobre a natureza brasileira, mas, sobretudo, a respeito de como seriam as evidências de geleiras a serem reconhecidas - claramente inculcando um 'modo de ver', um padrão geológico a ser reconhecido em campo quando aqui chegassem.

Hartt viajou com Agassiz em 1865 naquela que viria a ser a primeira de cinco visitas ao Brasil - todas as outras quatro sem Agassiz, é bom que se diga. Embora Hartt compartilhasse das expectativas de Agassiz, após algum tempo ele não mais compartilhou da mesma convicção acerca das glaciações quaternárias nesta região. Agassiz, pelo menos na mídia impressa, nunca admitiu haver mudado de opinião. Houve outros participantes na controvérsia, especialmente o brasileiro Guilherme Schüch de Capanema (1824-1908), que interpretou o ma- 
terial como não-glacial, resultante do intemperismo, mas nem Hartt nem Agassiz prestaram muita atenção em suas ideias. $\mathrm{O}$ conflito entre Louis Agassiz, o professor, e Charles Frederick Hartt, o aluno, mostra como uma evidência pode ser malinterpretada quando uma firme convicção, um modo de ver monolítico e previamente enraizado cria interferências na mente do observador, que resiste a outras interpretações, e como isso pode afetar o pensamento dos outros que estão na sua esfera de influência. As quatro expedições que Hartt conduziu sozinho representaram oportunidades de isolamento, "peregrinações científicas”, em que ele pode libertar-se do peso da autoridade de Agassiz e conquistar autonomia, confirmar suas próprias interpretações geológicas e produzir sua própria explicação geológica.

A postura intelectual fechada por parte de Agassiz enseja que se lembre do clássico texto de Chamberlin (1895) sobre o método das múltiplas hipóteses de trabalho em Geologia, no qual o autor defende que, ao investigar um problema geológico, deva-se formular diversas hipóteses explicativas sem escolher, a priori, nenhuma delas. E seguir trabalhando na coleta de dados e no raciocínio a fim de descartar as menos prováveis ou impossíveis, e ficar com a mais consistente ao final. Certamente, esta é a melhor atitude, tanto na prática e quanto no ensino também.

\section{Considerações finais}

De toda essa tentativa de reflexão usando a Filosofia e a História, o que resulta, em suma, para o ensino de Geociências? Penso que haja duas vertentes de conclusões possíveis. A primeira é o reforço de uma tese que o grupo reunido em torno do DGAE-IG/UNICAMP vem defendendo - e praticando em suas aulas - há décadas: aprender Geologia é fazer Geologia. Nas palavras do já citado Conrado Paschoale:

“(...) construir um modelo de aprendizado que não apenas seja um fazer Geologia, mas também a sua crítica. (...) Se os alunos quiserem saber o que é uma dobra, eu thes desenharei uma dobra na lousa. Depois, iremos ao campo ver como aquele diagrama é muito limitado, e discutir sua real utilização. E perceber como, em certas oportunidades, fixá-lo na cabeça pode até atrapalhar.” (Paschoale 1984: 5.248).
A segunda vertente toca os papéis educativos que a História e a Filosofia das Geociências podem desempenhar. Além de estimularem a visão crítica, de tornarem o pensamento mais maleável e apto a aceitar o contraditório, de mostrarem que as Ciências não se desenvolvem pela imposição, pura e simples, de verdades aceitas como definitivas sobre concepções tidas como erradas, de permitirem identificar os 'conceitos estruturantes' de conteúdos específicos, a Filosofia e a História podem facilitar o caminho para o surgimento da inovação em Geociências, tanto por meio da introdução de mudanças metodológicas em nossas práticas educativas e profissionais, quanto pela possibilidade de entender 'insights', abducções, ou mudanças gestálticas historicamente situadas. Dentro das limitações de nossos cursos de graduação, o emprego cuidadoso, bem selecionado e documentado de casos históricos controvertidos pode propiciar a experimentação e a compreensão de diversas situações de mudanças essenciais, em que múltiplas hipóteses de trabalho e teorias estavam em jogo, mas apenas uma acabou "vitoriosa" devido a uma série de fatores (muitos deles, inclusive, extra-científicos).

Assim, inovar - e renovar - nossas práticas educativas e profissionais é algo imprescindível e urgente, face aos desafios das mudanças globais que temos de enfrentar, como cientistas da Terra e, acima de tudo, como cidadãos do planeta.

\section{Referências}

Brice W.R., Figueirôa S.F.M. 2001. Charles Hartt, Louis Agassiz, and the controversy over Pleistocene glaciation in Brazil. History of Science, XXXIX:161-184.

Cohen B. 1993. A sense of history in science. Science \& Education, 2(3):251-277.

Compiani M. 1993. O papel do método das múltiplas hipóteses de trabalho no ensino de Ciências. Enseñanza de las Ciencias de la Tierra, 1(extra):4950.

Compiani M., Gonçalves P.W. 1996. Epistemologia e historia de la Geología como fuentes para la selección y organización del curriculum. Enseñanza de las Ciencias de la Tierra, 4(1):38-45.

Daston L., Galison P. 2007. Objectivity. New York: Zone Books. 501p.

Favera J.C.della, Medeiros M.A.M. 2007. Gestalt psychology and the recognition of complex sedimentary structures in geology. Rev. Bras. Geoc., 37(4):841-847.

Figueirôa S.F.M. 1989. Considerações sobre o papel 
da História da Geologia na formação dos geólogos. Rev. Bras. Geoc., 19(4):507-510.

Figueirôa, S.F.M., Lopes M.M. 1996. La historia de la geología y su potencial educativo: una reflexión desde América Latina. Enseñanza de las Ciencias de la Tierra, 4(1):71-76.

Gagliardi R. 1986. Los conceptos estructurales en el aprendizaje por investigación. Enseñanza de las Ciencias, 4(1):30-35.

Gagliardi R., Giordan A. 1986. La historia de las ciencias: una herramienta para la enseñanza. Enseñanza de las Ciencias, 4(3):253-258.

Guntau M., Kirschner E. 1984. The importance of the history of science for the university education of geologists. In: Int. Geological Congress, 27, Moscou, 1984. Abstracts..., v. VIII, p. 493-494.

Kuhn T.S. 1975. A estrutura das revoluções científicas. São Paulo: Ed. Perspectiva. 250p. (edição original da Univ. Chicago Press, 1962).

Laudan R. 1982. Tensions in the concept of geology: natural history or natural philosophy? Earth Sciences History, New York, 1:7-13.

Maienschein J., Smith G. 2008. What difference does history of science make, anyway? Isis, 99:318-321.

Mathews M.M. 1995. História, filosofia e ensino de Ciências: a tendência atual de reaproximação. Cadernos Catarinenses de Ensino de Física, 12(3):164214. Dezembro 1995. (trad. do original de 1992)

Obregón D. 1996. Ciencia e historia de las ciencias. In: J.J. Uribe, E. Quevedo. eds. 1996. Historia social de la ciencia en Colombia. Tomo X. Colômbia:
Colciencias, p.543-56.

Paschoale C. 1984. Alice no País da Geologia e o que ela encontrou lá. In: Cong. Bras. Geologia, 33, Rio de Janeiro, 1984. Anais..., Rio de Janeiro: SBG. v. XI, p. 5242-5249.

Rudwick M. 1996. Geological travel and theoretical innovation: the role of 'liminal' experience. Social Studies of Science, XXVI:143-59.

Rudwick M. 2005. Geology \& Genesis: a historical perspective on the interaction of two historical sciences. In: The Herbert Reynolds Lecture Series, Baylor Univ., Waco, Texas, USA URL: <http://www.baylor.edu/reynolds lecture_series/index.php?id $=38914>$. Acesso 9.setembro. 2008 .

Ruse M. 2002. Darwin and atheism: a marriage made in heaven? In: The Herbert Reynolds Lecture Series, Baylor Univ., Waco, Texas, USA URL: <http://www.baylor.edu/reynolds lecture_series/index.php?id=38914 $>$. Acesso 9.setembro. 2008.

Souza C.M.de. 2008. A presença do evolucionismo e do criacionismo em disciplinas do Ensino Médio: uma visão sob a ótica dos professores. Campinas: Instituto de Geociências, Unicamp. 162p. (Dissert. Mestrado).

Souza C.M.de, Figueirôa S.F.M. 2008. A História da Ciência como auxiliar na compreensão dos conflitos entre evolucionismo e criacionismo em disciplinas do ensino médio. In: Seminário Nacional de História da Ciência e da Tecnologia, 11, Niterói, 2008. Anais..., Niterói. Outubro 2008. 